
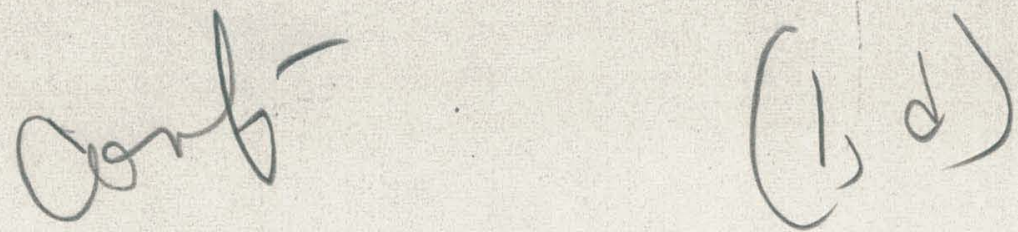

MASTER

\title{
A PROCEDURE FOR ESTIMATING PORE VOLUME AND AREA DISTRIBUTIONS FROM SORPTION ISOTHERMS*
}

\section{B. F. Roberts}

Reactor Chemistry Division, Oak Ridge National Laboratory**, Oak Ridge, Tennessee

Facsimile Price $\$$ Microfilm Price $\$$
Available from the
Office of Technical Services
Department of Commerce
Washington 25, D. C.
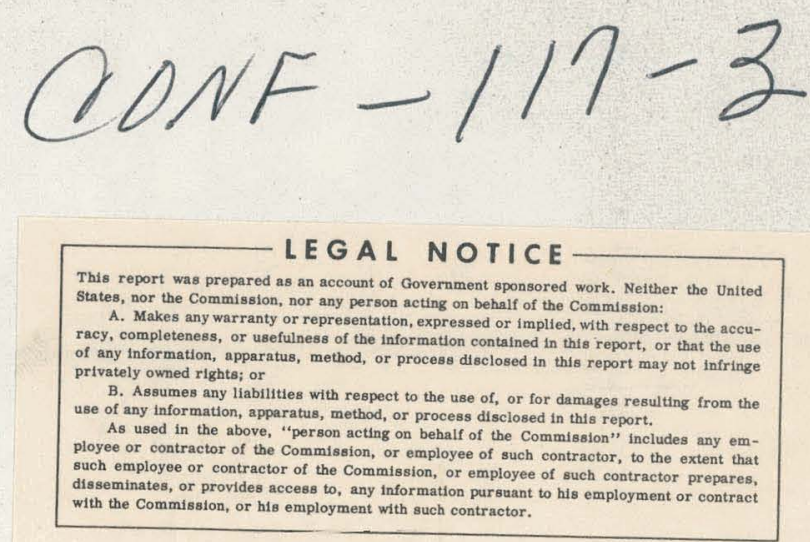

*For presentation at the 145th National Meeting of the American Chemical Society, New York City, September 8-13, 1963.

**Operated for the U. S. Atomic Energy Commission by Union Carbide Corporation.

American Chemical Society 145th National Meeting New York, New York September 8-13, 1963 


\section{DISCLAIMER}

This report was prepared as an account of work sponsored by an agency of the United States Government. Neither the United States Government nor any agency Thereof, nor any of their employees, makes any warranty, express or implied, or assumes any legal liability or responsibility for the accuracy, completeness, or usefulness of any information, apparatus, product, or process disclosed, or represents that its use would not infringe privately owned rights. Reference herein to any specific commercial product, process, or service by trade name, trademark, manufacturer, or otherwise does not necessarily constitute or imply its endorsement, recommendation, or favoring by the United States Government or any agency thereof. The views and opinions of authors expressed herein do not necessarily state or reflect those of the United States Government or any agency thereof. 


\section{DISCLAIMER}

Portions of this document may be illegible in electronic image products. Images are produced from the best available original document. 
Several procedures which utilize an analysis of desorption lsotherms have been proposed for estimating the distribution of pore volume and area of porous materials as a function of pore size. The more rigorous procedures such as the one described by Barrett, Joyner, and Halenda ${ }^{1}$ are based on the concept of simultaneous capillary condensation and multilayer adsorption. The procedure being presented today is a somewhat more rigorous application of this concept since no adjustable proportionality constants are required. It 18 also more simple and convenient to use.

The first step in the procedure is to transform the desorption 1sotherm of the porous material into units which are ultimately required. Thus, the amount adsorbed is expressed as IIquid volume. The relative pressure is expressed as pore radius by utilizing the classic Kelvin equation, a pore model, and the thickness of the layer adsorbed on the pore wails. Thickness as a function of pore radius is obtained from experimental isotherms on non-porous materials in a manner analogous to that of Barrett, Joyner, and Halenda; namely, the amount adsorbed per unit surface area 1s expressed as thickness, and the relative pressure is expressed as pore radius by again utillzing the Kelvin equation, the pore model, and the thickness. Slide I shows a typical transformed iso therm of a porous material. It is essentially a cumulative pore volume distribution having an abscissa which is fuliy corrected and an ordinate. which has yet to be corrected for multilayer adsorption.

The usual assumption is now made that all pores are filled by capillary condensation at a pore radius, $r_{j}$, corresponding to a spectfied large value of relative pressure. Other values of pore radius are then chosen as shown. The total amount desorbed, $w_{j}$, at any pore radius, $r_{j}$, equals the total observed vold volume of all pores are not filled by capillary condensation. 
Let us now consider how an adsorbed layer on the walls of a pore affects Its observed vold volume. For a pore of radius, $r$, slide 2 shows the ratio of Its actual physical volume, $V$, to its observed vold volume, $W_{f}$, when its walls are covered by an adsorbed layer of thickness, $t_{j}$. Now consider a porous material composed of pores of many different radil. For a single group of pores of average radius, $\bar{r}_{1}$, silde 3 shows the expression for the actual physical volume, $v_{1}$. Using one of these expressions, a general equation for the fth group of pores in a porous material composed of several groups of pores of different average radil is obtained by. mathematical induction.

To do this, the volume, $V_{1}$, of the group of pores having the largest average radius, $\bar{r}_{1}$, is first calculated as shown in slide 4 . At the relative pressure corresponding to $r_{1}$, the walls of this group of pores are covered by an adsorbed layer of thickness, $t_{1}$. Since this is the only group of pores not filled by capillary condensation, the total amount desorbed, $w_{1}$, equals $w_{1,1}$ and the volume, $V_{1}$, is easily calculated.

The volume of the group of pores having the next smaller average radius, $\bar{r}_{2}$, may now be calculated. It is necessary to note that, at the relative pressure corresponding to the pore radius $r_{2}$, there is an adsorbed layer of thickness, $t_{2}$, on the walls of both the group of pores of average radius $\bar{r}_{1}$ and the group of . average radius $\bar{r}_{2}$. Calculation of the volume, $v_{2}$, is seen to involve the previously calculated volume, $\mathrm{V}_{1}$.

Slide 5 shows the equation for the volume of the $j$ th group of pores having an average radius, $\bar{r}_{j}$. The calculation of this volume simply involves the total. amount desorbed at $r_{j}$, the previously calculated volume of all groups of pores having average radil larger than $\bar{r}_{j}$, and volume converision ratios $Q_{1, j}$ where $1 \leq \mathrm{j}$. The calculated pore area, $a_{j}$, of this group of pores equals twice the pore volume, $v_{j}$, divided by the average pore radius, $\bar{r}_{j}$ : 
This procedure is a rigorous application of the concept of simultaneous capillary condensation and physical adsorption. No adjustable proportionality constants are used. The equations are easily derived using any pore model for which the so-called Kelvin radius can be obtained. The procedure places no restrictions on the number or size of the increments which may be used. However, the most significant advantages of this procedure are the simplicity of Its use and the speed with which a distribution may be calculated. Slide 6 shows a table of $i / Q_{1, j}$ as a function of $\bar{r}_{1}, \bar{r}_{j}$, and $t_{j}$ used to perform the above sequence of calculations for a typical set of pore size groups. Even greatly expanded tables may be easily and quickly constructed using a slide rule or a desk calculator. The calculation of distributions from transformed 1sotherms using such a table may also be accomplished easily and quickly with a desk calculator. Because it is desired to process large numbers of distributions with complete freedom of increment size and using a minimum of manpower and to perform other calculations for each distribution, the equation for $\mathrm{V}_{\mathrm{g}}$ has been programmed for the IBM $7090^{\circ}$ computer although any small computer would be adequate.

This procedure is subject to the limitations common to all procedures which use the capillary condensation approach. First, the Kelvin equation may not be valid for the small pores. Second, the pore model may not be representative of the pore structure. Third, values of the thickness of the adsorbed layer may not represent a given sample, especially at low relative pressures, because of heat of adsorption effects. Fourth, errors may be introduced if pores larger than the maximum size used in the distribution calculation contribute an area equal to a significant fraction of the surface area of the sample. Existence of this condition is Indicated if the slope of the transformed isotherm at relative pressures greater than the previously mentioned specific value is significantly 


$$
-5-
$$

greater than zero. In such cases the transformed 1sotherm must be corrected properly in order to account for the amount adsorbed on these pores since this amount should not be included in the distribution calculation.

Data on elght samples of silica gel obtained and calculated according to the Barrett, Joyner, and Halenda procedure by Spencer ${ }^{2}$ have been calculated by this procedure. Slide 7 gives the total calculated pore volume, ratio of calculated surface area to the B.E.T. surface area, mean pore radius, median pore radius, and standard deviation for these samples as calculated by both procedures. It is seen that the procedures agree quantitatively. This agreement indicates the validity of the proportionality constant approach of Barrett, Joyner, and Halenda and also demonstrates the validity of the new procedure since the Barrett, Joyner, and Halenda procedure apparently agrees with the high pressure mercury intrusion method.

Inasmuch as Spencer evidently normalized his data on the basis of total pore volume, it is desirable to calculate the distributions on the basis of the unnormalized data and also to take advantage of the flexibility of the present procedure in regard to the chosen pore size increments. Slide 8 summarlzes the results of such calculations for both the cylindrical and parallel plate models. The displacement of the distributions probably reflects the fact that $r=r_{k}+t$ for the cylindrical pore model and $r=r_{k}+2 t$ for the parallel plate pore model. In conclusion, a rigorous procedure for estimating pore volume and area distributions from sorption 1sotherms has been developed. This procedure is easier and more conventent to use than previously published procedures. 


$$
\begin{gathered}
-6- \\
\text { References }
\end{gathered}
$$

I. E. P. Barrett, L. G. Joyner, and P. P. Halenda, J. Am. Chem. Soc. 73, 373 (1951).

2. W. B. Spencer,Jr $\cdot$, Determination of the Porous Properties of Some S1lica Gels, M. S. Thes18, Untversity of P1ttsburgh, 1950. 
UNCLASSIFIED

ORNL-DWG 63-693

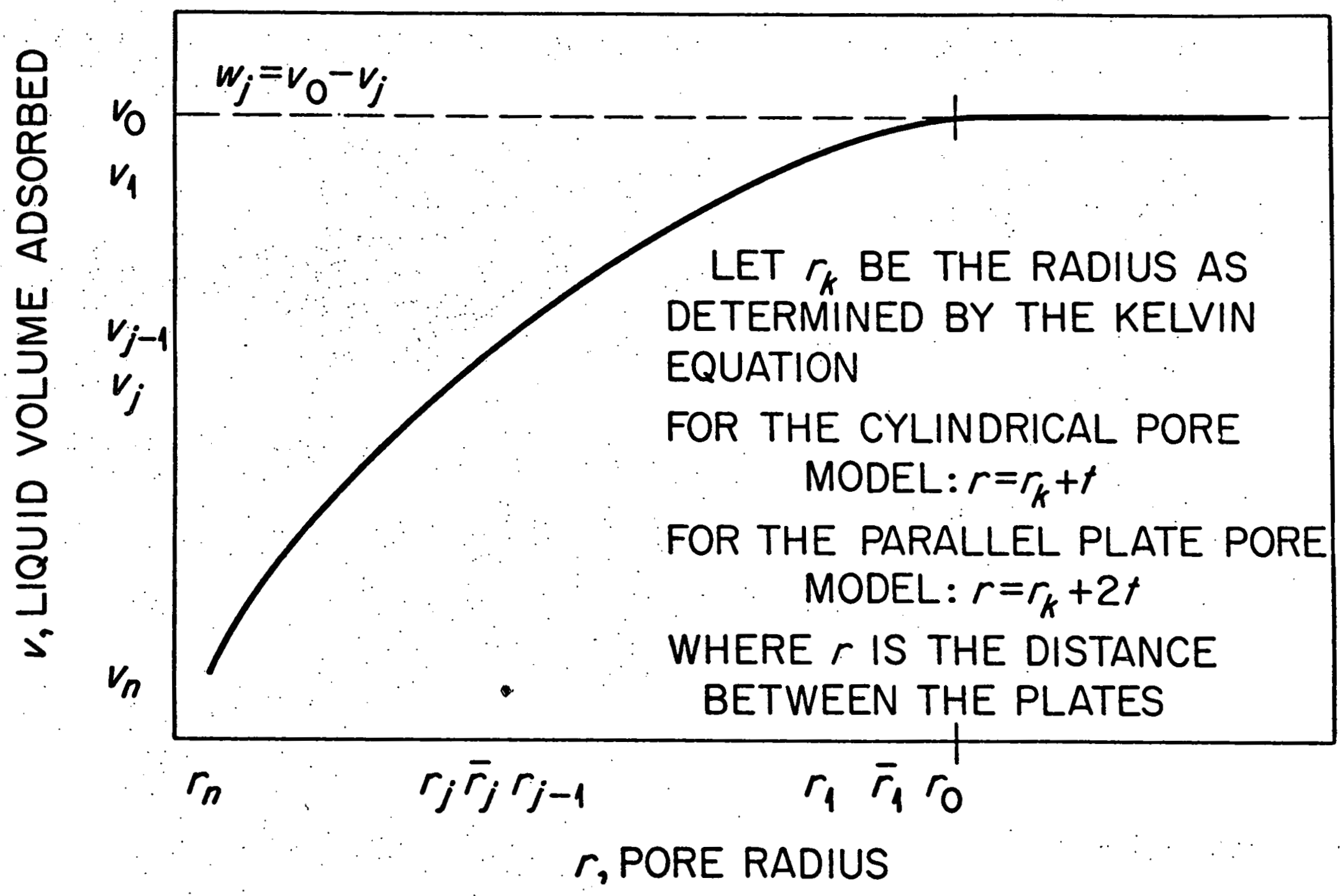

Typical Transformed Desorption Isotherm 


\section{UNCLASSIFIED}

ORNL DWG. 63-685

$$
\frac{V}{W_{j}}=\left(\frac{r}{r-t_{j}}\right)^{2}
$$

CYLINDRICAL PORE WHERE $r$ IS THE PORE RADIUS

$$
\frac{V}{W_{j}}=\left(\frac{r}{r-2 t_{j}}\right)
$$

PARALLEL PLATE PORE WHERE $r$ IS THE DISTANCE BETWEEN THE PLATES AND IS DEFINED. AS THE PORE RADIUS 


\section{UNCLASSIFIED \\ ORNL DWG. 63-681}

CYLINDRICAL PORE MODEL:

$V_{i}=\left(\frac{\bar{r}_{i}}{\bar{r}_{i}-t_{j}}\right)^{2} W_{i, j} \equiv Q_{i, j} W_{i, j}$

PARALLEL PLATE PORE MODEL:

$$
V_{i}=\left(\frac{\bar{r}_{i}}{\bar{r}_{i}-2 t}\right) W_{i, j} \equiv Q_{i, j} W_{i, j}
$$


AT $r_{1}$ WHERE THE TOTAL AMOUNT DESORBED, $w_{1}=w_{1,1}$,

$$
V_{1}=Q_{1,1} W_{1,1}=Q_{1,1} w_{1}
$$

AT $r_{2}$ WHERE THE TOTAL AMOUNT DESORBED, $w_{2}=W_{1,2}+w_{2,2}$,

$$
V_{2}=Q_{2,2} W_{2,2}=Q_{2,2}\left(w_{2}-W_{1,2}\right)=Q_{2,2}\left[w_{2}-\frac{V_{1}}{Q_{1,2}}\right]
$$


AT $r_{j}$ WHERE THE TOTAL AMOUNT DESORBED, $w_{j}=\sum_{i=1}^{j} w_{i, j}$,

$$
v_{j}=Q_{j, j}\left[w_{j}-\sum_{i=1}^{j-1} \frac{V_{i}}{Q_{i, j}}\right]
$$

WHERE

$$
Q_{i, j}=\left(\frac{\bar{r}_{i}}{\bar{r}_{i}-t_{j}}\right)^{2}
$$

CYLINDRICAL PORE MODEL

$$
Q_{i, j}=\left(\frac{\bar{r}_{i}}{\bar{r}_{i}-2 t}\right)
$$


$1 / Q_{i, j}$ AS A FUNCTION OF $\bar{r}_{i}, \bar{r}_{j}$, AND $t_{j}$ USING THE CYLINDRICAL PORE MODEL AND APPLIED TO A TYPICAL SET OF PORE SIZE GROUPS

\begin{tabular}{|c|c|c|c|c|c|c|c|c|c|c|c|c|}
\hline \multicolumn{3}{|c|}{ For $r_{0}=100 \mathrm{~A} \rightarrow i$} & 10 & 9 & 8 & 7 & 6 & 5 & 4 & 3 & 2 & 1 \\
\hline & & $t_{j}(\mathrm{~A})$ & 4.16 & 5.56 & 6.54 & 8.0 & 9.10 & 9.93 & 10.66 & 11.29 & 11.87 & 12.36 \\
\hline & & $r_{j}(\mathrm{~A})$ & 10 & 15 & 20 & 30 & 40 & 50 & 60 & 70 & 80 & 90 \\
\hline$\downarrow$ & & $\therefore \bar{r}_{j}(\mathrm{~A})$ & 12.5 & $17.5^{\circ}$ & 25.0 & 35.0 & 45.0 & 55.0 & 65.0 & .75 .0 & 85.0 & 95.0 \\
\hline$i$ & $r_{i}(A)$ & $\bar{r}_{i}(\mathrm{~A})$ & & & & & & & & & & \\
\hline 9 & 15 & 17.5 & 0.581 & & & & & & & & & \\
\hline 8 & 20 & 25.0 & 0.695 & 0.605 & & & & & & & & \\
\hline 7 & 30 & 35.0 & 0.776 & 0.708 & 0.661 & & & & & & & \\
\hline 6 & 40 & 45.0 & 0.824 & 0.768 & 0.730 & 0.676 & & & & & & \\
\hline 5 & 50 & 55.0 & 0.854 & 0.808 & 0.776 & 0.730 & 0.696 & & & & & \\
\hline 4 & 60 & 65.0 & 0.876 & 0.836 & 0.809 & 0.769 & 0.740 & 0.718 & & & & \\
\hline 3 & 70 & 75.0 & 0.892 & 0.857 & 0.833 & 0.798 & 0.772 & 0.753 & 0.736 & & & - \\
\hline 2 & 80 & 85.0 & 0.904 & 0.873 & 0.852 & 0.821 & 0.797 & 0.780 & 0.765 & 0.752 & & \\
\hline 1 & 90 & 95.0 & 0.914 & 0.886 & 0.867 & 0.839 & 0.818 & 0.802 & 0.788 & 0.776 & 0.766 & \\
\hline$i$ & ${ }^{r_{j}}$ & $\overline{\boldsymbol{r}}_{j}$ & 0.445 & 0.466 & 0.545 & 0.595 & 0.636 & 0.671 & 0.699 & 0.722 & 0.740 & 0.757 \\
\hline
\end{tabular}


UNCLASSIFIED

ORNL DWG. 63.682

COMPARISON OF VOLUME WEIGHTED PORE SIZE DISTRIBUTIONS

CALCULATED BY THE NEW PROCEDURE AND THE B.J.H.

PROCEDURE USING THE CYLINDRICAL MODEL

\begin{tabular}{|c|c|c|c|c|c|c|}
\hline Sample & Procedure & $\begin{array}{l}\sum_{j=1}^{n} v_{j} \\
\mathrm{~cm}^{3} / \mathrm{g}\end{array}$ & $\frac{\text { SA(P.S.D.) }}{\text { SA(B.E.T.) }}$ & $\begin{array}{l}\text { Mean Pore } \\
\text { Radius, A }\end{array}$ & $\begin{array}{c}\text { Median Pore } \\
\text { Radius, A }\end{array}$ & $\frac{\sqrt{\text { Variance }}}{A}$ \\
\hline S-17(A) & New & 0.4714 & 1.045 & 16.2 & 18.3 & 4.02 \\
\hline S- $17(A)$ & B.J.H. & 0.4635 & 1.026 & 16.2 & 18.3 & 4.01 \\
\hline S-17(B) & New & 0.8406 & 1.105 & 46.2 & 43.3 & 15.01 \\
\hline S-17(B) & B.J.H. & 0.8141 & 1.064 & 46.6 & 44.0 & 15.33 \\
\hline S-17(C) & New & 0.9861 & .1 .135 & 80.9 & 78.6 & 20.30 \\
\hline S-17(C) & B.J.H. & 0.9660 & 1.096 & 81.6 & 79.0 & 14.06 \\
\hline S-17(D) & New & 0.8251 & 1.220 & 37.4 & 36.8 & 8.96 \\
\hline$S-17(D)$ & B.J.H. & 0.7751 & 1.159 & 36.3 & $37: 0$ & 13.55 \\
\hline S-17(E) & New & 0.7213 & 1.002 & 63.7 & 64.5 & 13.14 \\
\hline S-17(E) & B. J.H. & 0.7073 & 0.984 & 64.0 & 64.8 & 12.64 \\
\hline $5-17(F)$ & New & 0.3970 & 1.078 & 23.6 & 23.2 & 4.12 \\
\hline S- $17(F)$ & B.J.H. & 0.3926 & 1.072 & 23.5 & 23.4 & 4.14 \\
\hline S-17(G) & New & 0.4065 & 1.097 & 50.8 & 53.9 & 9.20 \\
\hline S-17(G) & B.J.H. & 0.3926 & 1.041 & 51.4 & 54.2 & 8.57 \\
\hline S. $17(\mathrm{H})$ & New & 0.4349 & 1.055 & 22.3 & 22.5 & 3.26 \\
\hline S- $17(H)$ & B.J.H.: & 0.4253 & 1.030 & 22.4 & 22.5 & 3.24 \\
\hline
\end{tabular}


Slide 8

UNCLASSIFIED

ORNL DWG. 63.684

COMPARISON OF VOLUME WEIGHTED PORE SIZE DISTRIBUTIONS CALCULATED BY THE NEW PROCEDURE USING CYLINDRICAL AND PARALLEL PLATE MODELS

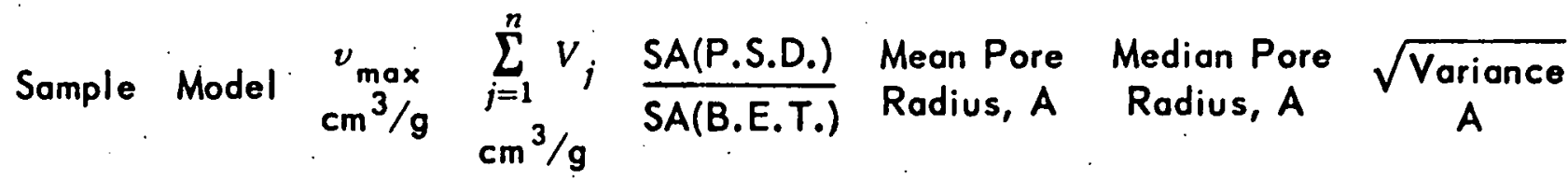

\begin{tabular}{lllllllll}
\hline S-17(A) & Cyl. & 0.4619 & 0.3588 & 0.690 & 17.7 & 18.8 & 3.020 \\
S-17(A) & P.P. & 0.4619 & 0.3735 & 0.598 & 22.0 & 24.3 & 4.969 \\
S-17(B) & Cyl. & 0.8053 & 0.8419 & 1.116 & 44.4 & 41.6 & 13.03 \\
S-17(B) & P.P. & 0.8053 & 0.8112 & 0.923 & 53.1 & 51.0 & 14.07 \\
S-17(C) & Cyl. & 0.9545 & 0.9928 & 1.200 & 77.9 & 77.1 & 20.98 \\
S-17(C) & P.P. & 0.9545 & 0.9753 & 1.030 & 89.6 & 89.1 & 22.63 \\
S-17(D) & Cyl. & 0.7678 & 0.7873 & 1.142 & 37.5 & 36.5 & 11.70 \\
S-17(D) & P.P. & 0.7678 & 0.7553 & 0.900 & 46.0 & 45.0 & 11.76 \\
S-17(E) & Cyl. & 0.7032 & 0.7211 & 1.037 & 62.8 & 64.2 & 14.96 \\
S-17(E) & P.P. & 0.7032 & 0.7023 & 0.858 & 72.9 & 74.8 & 16.03 \\
S-17(F) & Cyl. & 0.4063 & 0.4014 & 1.088 & 24.0 & 23.0 & 5.416 \\
S-17(F) & P.P. & 0.4063 & 0.3739 & 0.783 & 30.8 & 29.0 & 6.088 \\
S-17(G) & Cyl. & 0.3942 & 0.4044 & 1.112 & 50.8 & 53.6 & 11.86 \\
S.17(G) & P.P. & 0.3942 & 0.3923 & 0.904 & 60.3 & 64.4 & 12.93 \\
S-17(H) & Cyl. & 0.4213 & 0.4198 & 1.060 & 21.9 & 22.0 & 4.372 \\
S-17(H) & P.P. & 0.4213 & 0.4145 & 0.860 & 27.6 & 29.3 & 6.400 \\
\hline
\end{tabular}

